\title{
Providing cardiothoracic services in 2035: Signs of trouble ahead
}

\author{
Susan Moffatt-Bruce, MD, PhD, MBA, ${ }^{\mathrm{a}}$ Juan Crestanello, MD, ${ }^{\mathrm{a}}$ David P. Way, MEd, ${ }^{\mathrm{b}}$ and \\ Thomas E. Williams, Jr, MD, $\mathrm{PhD}^{\mathrm{a}}$
}

\section{ABSTRACT}

Objective: As the population ages, we will present the reality around being able to meet the health care needs of our population. In particular, we will present that providing cardiothoracic services in 2035 with a shortage of surgeons and an unknown caseload may be an impossibility.

Methods: By using data from the American Board of Thoracic Surgery, we estimate that in 2010, 4000 cardiothoracic surgeons performed more than 530,000 cases. Additionally, cardiothoracic residency programs train and certify on average 90 new surgeons every year. To estimate the number of cases for 2035, we consulted the Census Bureau figures for 2010 and population projections for 2035. We then estimated the expected caseload for cardiothoracic surgeons relative to heart surgery, as well as lung and esophageal surgery. We found that among 2010 cardiothoracic surgeons in the United States, they completed more than 530,000 cases.

Results: We project that by 2035 there will be 853,912 cases to perform, representing an increase from 2010 to 2035 of approximately $61 \%$ nationally. The cases per surgeon, per year, in 2010 averaged 135 for almost each of the 4000 surgeons. In 2035, the average caseload per surgeon will be 299 cases, representing an increase of $121 \%$ for the individual surgeon.

Conclusions: We conclude that by 2035, cardiothoracic surgeons will be responsible for more than 850,000 patients requiring surgery. This represents a $61 \%$ increase in the national case load and a potential for a $121 \%$ increase for each cardiothoracic surgeon. We believe this is not feasible and a sign of trouble ahead. (J Thorac Cardiovasc Surg 2018;155:824-9)

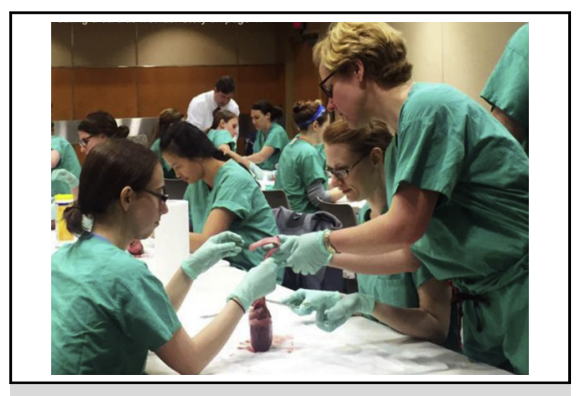

Our students and residents are the future of CT surgery.

\section{Central Message}

As CT surgeons, we are at risk of experiencing a workforce shortage by 2035 . This is due to an imbalance in the supply and demand curves of CT services.

\section{Perspective}

As the population ages, we will present the reality around being able to meet the needs of our population. In particular, we will reveal that providing CT services in 2035 with a shortage of surgeons and an increasing caseload may be an impossibility.

See Editorial Commentary page 830.

See Editorial page 822 .
As the population ages, we will present our concern as to whether we, as the profession of cardiothoracic (CT) surgeons, will be able to meet the needs of our population. In particular, we will present that providing CT services in 2035 with a shortage of surgeons and an unknown caseload may be an impossibility. It has been previously shared that

From the ${ }^{\mathrm{a}}$ Department of Surgery, The Ohio State University; and ${ }^{\mathrm{b}}$ Department of Emergency Medicine, College of Medicine, The Ohio State University, Columbus, Ohio.

Read at the 96th Annual Meeting of The American Association for Thoracic Surgery, Baltimore, Maryland, May 14-18, 2016.

Received for publication May 26, 2016; revisions received Aug 13, 2017; accepted for publication Sept 1, 2017; available ahead of print Dec 6, 2017.

Address for reprints: Susan Moffatt-Bruce, MD, PhD, MBA, 130 Doan Hall, 410 West 10th Ave, Columbus, OH 43210 (E-mail: Susan.moffatt-bruce@osumc.edu). 0022-5223/\$36.00

Copyright (c) 2017 by The American Association for Thoracic Surgery

https://doi.org/10.1016/j.jtcvs.2017.09.135 we will have a projected shortage of all surgeons and in particular CT surgeons as early as $2020 .^{1-4}$ CT surgeons will continue to be of importance to all health care systems because cardiovascular disease is likely to remain the leading cause of mortality and morbidity for the elderly with approximately 600,000 people dying of heart disease in the United States every year, equating to 1 in every 4 deaths. ${ }^{5}$ Likewise, thoracic surgeons will remain a

Scanning this QR code will take you to a supplemental video. To view the AATS Annual Meeting Webcast, see the URL next to the webcast thumbnail. 


\section{Abbreviations and Acronyms \\ ABTS $=$ American Board of Thoracic Surgery \\ $\mathrm{CT}=$ cardiothoracic}

vital part of all preventative and intervention strategies, with lung cancer being the second most common cause of death among both men and women. ${ }^{6}$ These statistics are coupled with the fact that the applications for fellowship in the specialty of CT surgery have decreased. ${ }^{7}$ The concern raised previously was that there were fewer surgeons training to become CT surgeons and that fewer are actually successful once admitted to the residency training program. The American Board of Thoracic Surgery (ABTS) data reveal that the number of certificates being awarded to residency graduates is ultimately declining. ${ }^{7}$ Since 1996, the ABTS has awarded approximately 2335 new certificates through 2014, averaging 123 per year. The fact that the number of ABTS certificates, and therefore qualified CT surgeons, has decreased from a high of 168 in 1998 to only 90 in 2014 is extremely concerning. ${ }^{7}$

Consequently, increases in the population who will need surgical interventions for treatment of cardiovascular disease or thoracic malignancies, coupled with predicted decreases in the CT surgeon workforce, will lead to severe shortages in the delivery of surgical services by the year 2035. We present some of the realities that we must face considering the certainty of an inability to provide patients with the correct level of CT services.

\section{FRAMING THE PROBLEM}

By using data from the ABTS and the Society of Thoracic Surgeons, we estimated case volume for CT surgeons. ${ }^{8}$ To estimate the numbers of cases needed to be performed in 2035, we thought it reasonable to consult the Census Bureau figures for 2010 and population projections for 2035. In 2010 , we had a national population of $310,233,000$, of whom 40,229,000 were aged 65 years and older. In 2035, we are projected to have a population of $389,531,000$ of whom 77,543,000 will be aged 65 years and older.'

We base many of our conclusions on the hypothesis that $50 \%$ of the heart surgery cases will be performed on those aged less than 65 years and that $50 \%$ will be performed on those aged 65 years and older (The Society of Thoracic Surgeons, personal communication, July 2011). For lung cancer, the breakdown of cases by age is anticipated to be $30 \%$ in those aged less than 65 years and $70 \%$ in those aged 65 years and older. ${ }^{6,10}$ For esophageal surgery, the breakdown of cases by age is $37 \%$ in those aged less than 65 years and $63 \%$ in those aged more than 65 years. ${ }^{11}$

To calculate the expected caseload for CT surgeons, we estimated the increase by multiplying the cases in 2010 by the percentage increase in population separately by age group: aged less than 65 years and 65 years and older (ie,

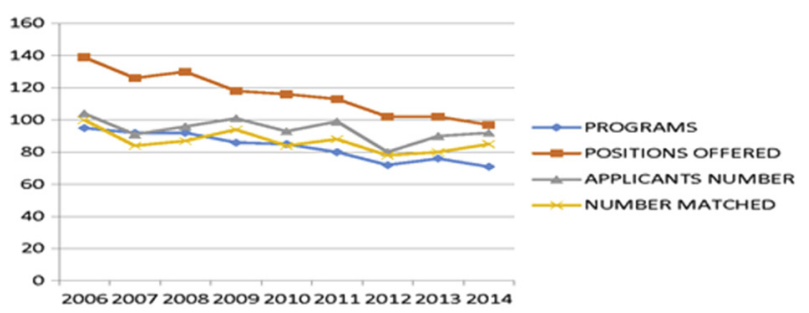

FIGURE 1. The supply of CT surgeons is decreasing dramatically. The number of programs that exist to train CT surgeons is decreasing on a yearly basis, as are the number of positions for training being offered.

case load $\times \%$ population increase). For instance, for heart surgery we split the number of total cases equally between age groups (50:50) and then estimated the expected number of cases for each age group separately using the expected increase in population: $15.5 \%$ for those aged less than 65 years and $92.8 \%$ for those aged 65 years and more (The Society of Thoracic Surgeons, personal communication, July 2011). We completed the same calculations for lung and esophageal cancers. For lung cancer, the figures are $30 \%$ for those aged less than 65 years and $70 \%$ in those aged 65 years and older. ${ }^{6}$ For esophageal surgery, the figures are $37 \%$ for those aged less than 65 years and $63 \%$ for those aged more than 65 years. ${ }^{11}$

\section{Increasing Demand Is Evident}

Therefore, amid all these assumptions, which we think are reasonable, clearly the demand for CT surgeons is increasing for both cardiovascular diseases and thoracic malignancies. With approximately 4000 CT surgeons performing more than 291,000 heart cases and participating in more than 230,000 lung and esophageal cases, the problem is very real. ${ }^{6,11}$ There is not only a demand problem but also a supply imbalance. There continues to be a decrease in the number of CT surgery residents who are successfully graduating. Not only are the number of applicants decreasing, but also the oral examination failure rates are approximately $30 \%$ and the written failure rate is approximately $20 \%$. Taken together, with the average number of positions filled remaining at less than 100 for the last 7 years, the supply is at risk (Figure 1). For the thoracic surgery workforce, there will be less than 3000 practicing CT surgeons by 2035, which represents a shortage of approximately $27 \%$. This estimate of the CT workforce is based on the assumptions of 1.42 surgeons for every 100,000 people, 133 CT surgeons retiring each year, and only 90 graduating residents every year. ${ }^{3}$

\section{The Result of the Increasing Demand With Dwindling Supply}

Considering the increase in the number of patients with both cardiac and thoracic malignancies, there is an imbalance of the supply and demand curves. In 2035, the 
TABLE 1. Number of cardiothoracic cases predicted for 2035

\begin{tabular}{|c|c|c|c|c|c|}
\hline Category & \multirow[t]{2}{*}{ No. of cases per year } & \multicolumn{2}{|c|}{ No. of cases per year by age groups } & \multirow[t]{2}{*}{ Thoracic surgeons } & \multirow[t]{2}{*}{ Cases per surgeon per year } \\
\hline Year 2010 & & & & & \\
\hline \multirow{2}{*}{ Heart surgery } & 291,410 & $>65$ & 145,705 & 3928 & 74 \\
\hline & & $<64$ & 145,705 & & \\
\hline \multirow[t]{2}{*}{ Lung cancer cases } & 222,520 & $>65$ & 155,764 & 3928 & 57 \\
\hline & & $<64$ & 66,756 & & \\
\hline \multirow[t]{2}{*}{ Esophageal cases } & 16,640 & $>65$ & 10,483 & 3928 & 4 \\
\hline & & $<64$ & 6157 & & \\
\hline \multirow[t]{2}{*}{ Totals } & 530,570 & $>65$ & 311,952 & & 135 \\
\hline & & $<64$ & 218,618 & & \\
\hline \multicolumn{6}{|l|}{ Year 2035} \\
\hline \multirow[t]{2}{*}{ Heart surgery } & 449,213 & $>65$ & 280,852 & 2865 & 157 \\
\hline & & $<64$ & 168,361 & & \\
\hline \multirow[t]{2}{*}{ Lung cancer cases } & 377,377 & $>65$ & 300,241 & 2865 & 132 \\
\hline & & $<64$ & 77,136 & & \\
\hline \multirow[t]{2}{*}{ Esophageal cases } & 27,321 & $>65$ & 20,207 & 2865 & 10 \\
\hline & & $<64$ & 7114 & & \\
\hline \multirow[t]{2}{*}{ Totals } & 853,912 & $>65$ & 601,300 & & 299 \\
\hline & & $<64$ & 252,612 & & \\
\hline \multirow[t]{2}{*}{ Overall increase 2010 to 2035} & $60.9 \%$ & $>65$ & $92.8 \%$ & & $121 \%$ \\
\hline & & $<64$ & $15.5 \%$ & & \\
\hline
\end{tabular}

Sources: Society of Thoracic Surgeons Adult Cardiac Surgery Database 2015 and Executive Summary, American Cancer Society and Cancer Fact 2010.

average caseload per surgeon will be 299 cases, which is a resulting increase of $121 \%$ for the individual surgeon (Table 1). There is an approximately $61 \%$ increase in both cardiac and thoracic cases by 2035 , which is a result of an approximate $26 \%$ increase in the population. This increase in demand is coupled with a projected approximate $27 \%$ decrease in CT surgeons by 2035 , as demonstrated by the supply and demand curve (Figure 2).

Our study reveals that the number of potential cases for every CT surgeon will increase disproportionately as we move toward 2035. We have previously presented the concerning fact that there will not be a sufficient number of trained CT surgeons to care for the growing American

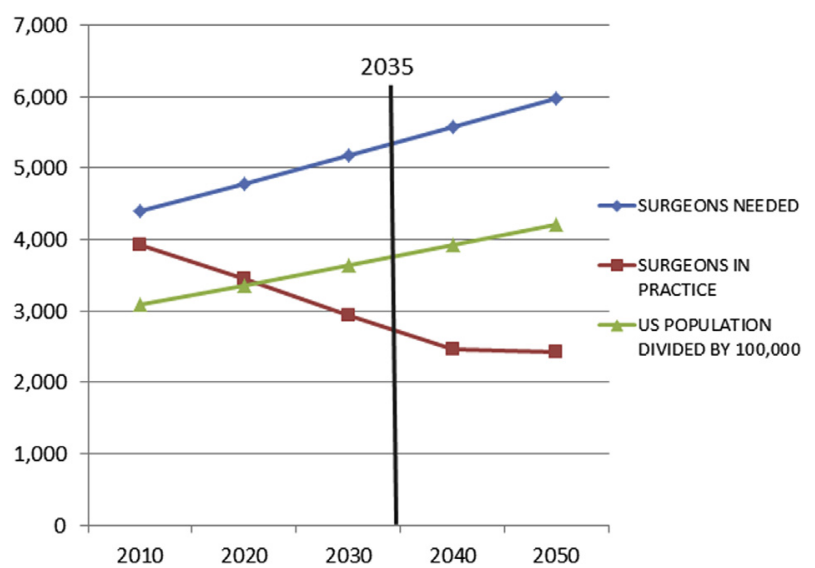

FIGURE 2. Supply and demand curve for CT surgery. The big picture for CT surgery as a profession demonstrates that we are decreasing in numbers as practitioners, and this is coupled with both an increase in the population and an overall need for surgeons. population. ${ }^{3,7}$ The timing of the resultant shortfall has been projected to happen between 2020 and $2030 .^{2,3} \mathrm{We}$ further our projection to 2035 in this opinion article because that is when there is projected to be a $92 \%$ increase in the population aged more than 65 years. ${ }^{9}$ There are fewer applicants to CT surgery training programs and fewer successful graduates, and now we fear each of these graduates will be faced with a significant and potentially unprecedented workload.

\section{The Problem and Potential Solutions for the Future}

How do we increase the supply of CT surgeons to meet the increasing demand of our population and patients? In this new era of value-based provision of care models, there will come a time when CT surgeons' remuneration will be based on quality, and therefore the ever-evasive "quality-adjusted relative value unit" will have to be defined. Overall geographic location is the most important work choice consideration ( $69 \%$ ) for new physicians, followed by lifestyle $(61 \%)$ and adequate call coverage/personal time $(60 \%)$ and a good financial package $(60 \%)^{12-16}$ Other innovative programs that incentivize medical students to join our ranks are absolutely key to our continued success. Programs such as the Johns Hopkins for medical students and the Ohio State University Summer Scholars program can potentially augment the supply of CT surgeons. ${ }^{17,18}$ Of 7 students who participated in our Summer Scholars program in recent years, 4 have said that they want to pursue CT surgery. ${ }^{17}$

Perhaps we need to look at CT surgery as a business and manage it accordingly. In the Harvard Business Review, Porter ${ }^{19}$ eloquently outlines and defines the 5 


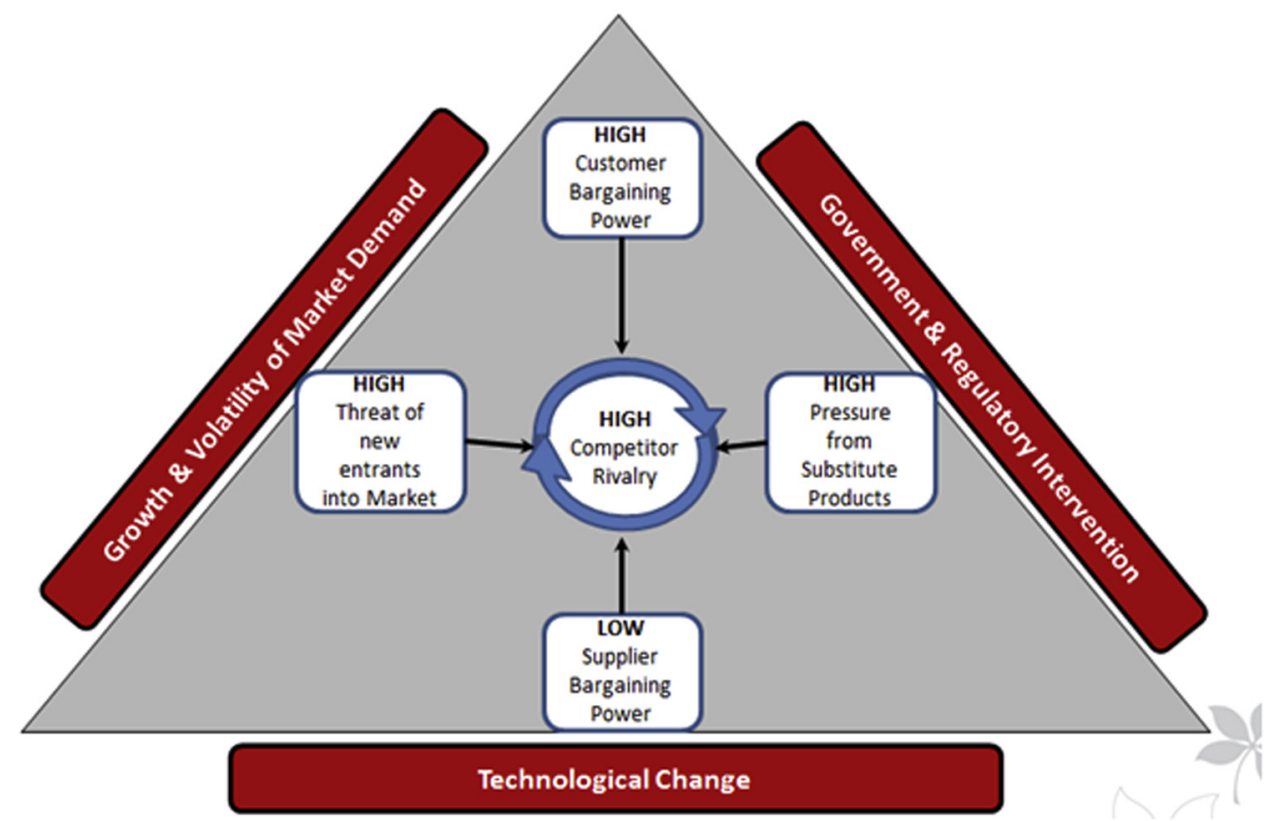

FIGURE 3. Porter's 5 forces as it pertains to CT surgery. Barriers to entry could be defined as high. Supplier bargaining applied to CT surgery is low. The threat of a substitute product is high. The threat of the bargaining power of customers, either patients or payers, is high. The intensity of rivalry is high.

competitive forces that shape strategy in $2008 .{ }^{19} \mathrm{He}$ clearly articulates that competition within an industry may be defined too narrowly and goes beyond the traditional rivals that currently exist and should be expanded to 4 other forces, other than rivalry, including barriers to entry, suppliers' substitute products, and customers (Figure 3).

Barriers to entry as a CT surgery trainee could be defined as high if we consider that unless we act now, there are unlikely to be other programs established (supply), and it requires a large amount of money to train a surgeon (capital requirements). Supply barriers can be perceived as low because there is an increasing supply of patients with disease. The threat of a substitute product or service references the opportunity for a consumer to switch to a like product or service; applied to CT surgery, this threat is high. The transcatheter aortic valve replacement and mitral valve clip innovations are 2 examples. These may reduce the resident experience and their success in becoming proficient in "routine" cardiac surgery.

Last, the threat of the bargaining power of customers, either patients or payers, is high. Surgeons and practice will have to be sensitive of their patients' perceived inherent tension to remain loyal yet still get value for money. As consumers are being increasingly burdened with higher percentages of the total cost of health care, there will be an increasing scrutiny of pricing for all health care services. Overall, the intensity of rivalry in CT surgery is high. The bar to be admitted to a medical school and then to a revered CT surgery residency is competitive. The impact of the I6 training programs has, as of yet, an undefined effect on the overall health of CT surgery residencies.

Therefore, in summarizing Porter's ${ }^{19}$ framework of analysis, if the forces are high and intense, almost no company earns attractive return on investment compared with if the forces are low and the environment hospitable.

\section{CONCLUSIONS}

By 2035, CT surgeons will be responsible for providing surgical care to more than 850,000 patients, which represents a $61 \%$ increase in the national case load and a potential for a $121 \%$ increase in cases for each CT surgeon. The potential solution proposed for each surgeon to cover

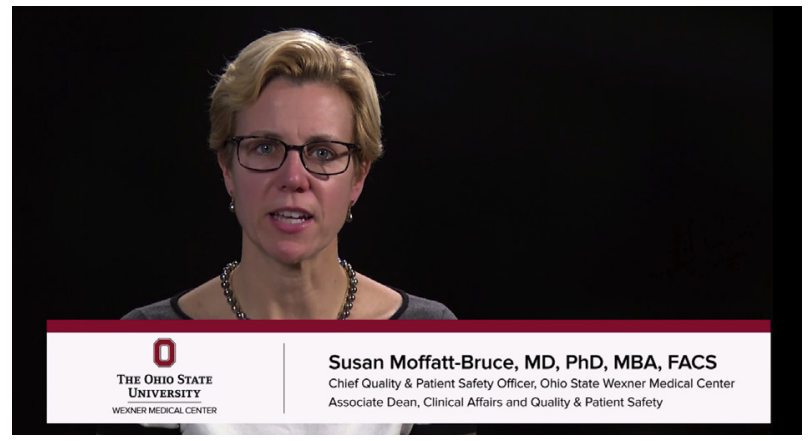

VIDEO 1. Dr Moffatt-Bruce and Dr Williams provide a description of the signs of trouble ahead that are outlined in the article, in particular, the reality of the supply and demand of CT surgeons that is unequal and will serve to imbalance the practice of CT surgery. Video available at: http:// www.jtcvsonline.org/article/S0022-5223(17)32387-5/fulltext. 
more cases will be a limited one, because it will undoubtedly hinder academic endeavors, innovation, and surgeon growth. Ultimately, it will also detract from the attractiveness of CT surgery as a whole and will only serve to render us less competitive as a specialty. We present this study to highlight the sign of trouble ahead that must be addressed head-on to increase the number of those successfully trained and successfully practicing in what has become a competitive market (Video 1).

\section{Webcast}

You can watch a Webcast of this AATS meeting presentation by going to:

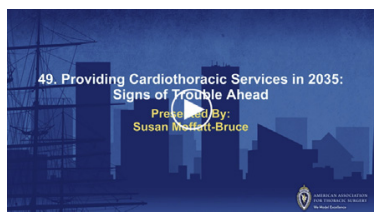

\section{Conflict of Interest Statement}

Authors have nothing to disclose with regard to commercial support.

\section{References}

1. Williams TE, Satiani B, Thomas A, Ellison EC. The impending shortage and the estimated cost of training the future surgical workforce. Ann Surg. 2009;250:590-7.

2. Grover A, Gorman K, Dall TM, Jonas R, Lytle B, Shemin R, et al. Shortage of cardiothoracic surgeons is likely by 2020. Circulation. 2009;120:488-94.

3. Williams TE Jr, Sun B, Ross P Jr, Thomas AM. A formidable task: population analysis predicts a deficit of 2,000 cardiothoracic surgeons by 2030. J Thorac Cardiovasc Surg. 2010;139:835-40.

4. Williams TE Jr, Satiani B, Ellison EC. The Coming Shortage of Surgeons: Why They Are Disappearing and What That Means for Our Health. Santa Barbara, CA: Praeger: ABC-CLIO, Greenwood; 2009:1-21.

5. National Center for Health Statistics. Health, United States, 2014. Table 20 Leading causes of death and numbers of deaths, by sex, race, and Hispanic origin: United States, 1980 and 2013. Available at: http://www.cdc.gov/nchs/data/hus/ hus14.pdf\#020. Accessed April 5, 2016.

6. SEER Cancer Statistics Factsheets: Lung and Bronchus Cancer. National Cancer Institute, Bethesda, MD. Available at: http://seer.cancer.gov/statfacts/html/lungb. html. Accessed March 2, 2016.

7. Moffatt-Bruce SD, Ross P, Williams TE Jr. American Board of Thoracic Surgery Examination: fewer graduates, more failures. J Thorac Cardiovasc Surg. 2014; 147:1464-9.

8. The Society of Thoracic Surgeons. Society of Thoracic Surgeons, adult cardiac surgery database, executive summary period ending 12/31/2015. Available at: https://www.sts.org/sites/default/files/documents/ACSD_2016Harvest1_Executive Summary.pdf. Accessed November 17, 2017.

9. Population Division, US Census Bureau. Table 2. Projections of the population by selected age groups and sex for the United States 2010 to 2050 (NP2008-T2). Release Date: August 14, 2008. Accessed March 3, 2016.

10. American Cancer Society. Cancer facts and \& figures, 2010. Available at: https:// www.cancer.org/research/cancer-facts-statistics/all-cancer-facts-figures/cancerfacts-figures-2017.html. Accessed November 14, 2016.

11. National Institutes of Health. SEER cancer statistics factsheets: esophageal cancer. National Cancer Institute, Bethesda, MD. Available at: http://seer.cancer. gov/statfacts/html/esoph.html. Accessed March 2, 2016.

12. Staiger DO, Marshall SM, Goodman DC, Auerbach DI, Buerhaus PI. Research Letter: Association Between Having a Highly Educated Spouse and Physician Practice in Rural Underserved Areas. JAMA. 2016;315:939-41.
13. Satiani B, Williams TE, Brod H, Way DP, Ellison EC. A review of trends in attrition rates for surgical faculty: a case for a sustainable retention strategy to compete with demographic and economic realities. J Am Coll Surg. 2013;216:944-53.

14. Cummins J. HealthLeaders Media, January 12, 2014. Available at: www. healthleadersmedia.com.

15. Cjeka Search. Physician compensation report. Available at: http://www. cjekasearch.com/physician-compensation-report. Accessed March 1, 2016.

16. Hawkins M. Review 2013 of physician and advanced practitioner recruiting incentives. Available at: http://www.merritthawkins.com/uploadedFiles/Merritt Hawkins/Pdf/2013_Review_of_Recruiting\%20Incentives_Preview.pdf. Accessed March 7, 2016.

17. Gott VL, Patel ND, Yang SC, Baumgartner WA. Attracting outstanding students (premedical and medical) to a career in cardiothoracic surgery. Ann Thorac Surg. 2006;82:1-3.

18. Higgins RSD, Kilic A, Daniel V, Merritt R, Moffatt-Bruce S, Crestanello J. Recruiting the best \& brightest into CT surgery: medical student summer scholars revisited. Presented at: Society of Thoracic Surgeons Annual Conference; January 24-28, 2015; San Diego, CA.

19. Porter M. The five competitive forces that shape strategy. Harv Bus Rev. 2008;86: 2-18.

Key Words: education, resources, workforce

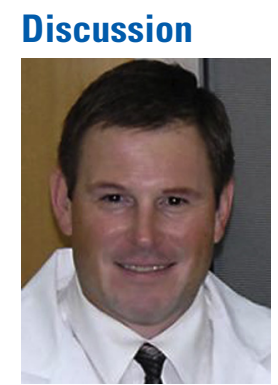

Dr J. Ikonomidis (Charleston, SC). The data you're presenting are a reiteration of information that we've known for some time, as we have told since the start of the millennium that a potential workforce crisis looms for us.

I have a few questions for you. The first is, can you comment on adjusting the numbers that you've quoted based on advancements in new technologies? We have low-risk transcatheter aortic valve replacement looming on the horizon, advancements in percutaneous mitral valves, and novel thoracic oncologic technologies. How do you think these will affect the numbers in your projections?

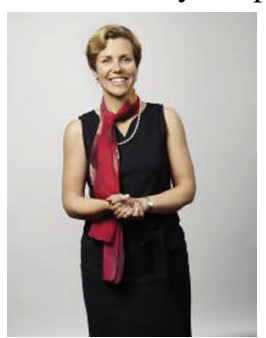

Dr Susan Moffatt-Bruce (Columbus, Ohio). The new technologies potentially reflect new entrants into this market and may reduce some of the caseload for all surgeons. Then we will have perhaps an even higher barrier and will shift the force toward a different skill set. Obviously, as CT surgeons want to embrace the existent surgical environment, we will still have an increase in our workload, but perhaps not to the same degree. We will still look at these numbers regardless of new entrants, and they will still be disproportionately high relative to our current and future capacity.

Dr Ikonomidis. One thing about your presentation that I found particularly troubling was the projected increase in population juxtaposed against the decline in graduating residents and ABTS certificates. It remains concerning that in the light of these disturbing workforce projections, 
not only were more training programs not implemented, but also we've actually lost many.

Could you comment on what you see as the barriers to the successful completion of residency training and how we can mitigate the loss of residency programs and perhaps create new ones and expand the work force even in the short term?

Dr Moffatt-Bruce. The first item of business for us is really to make our residencies attractive. I think looking at some of the data that are out there indicate that allowing for flexible duty hours and meeting the needs of the changing resident expectations will be absolutely key. I think the FIRST trial, as published in the New England Journal of Medicine, was helpful to show us that we can meet the needs of residents and that we can do this without harming patients.

I think that looking at the optimal number of residents who we are recruiting and training, and strategically locating graduate residents in the correct geographic locations relative to the need for cardiovascular and thoracic malignancies cases will be absolutely key. Understanding and addressing the gap of where they are training and where our residents end up and ultimately establish practices will be absolutely key to our success.

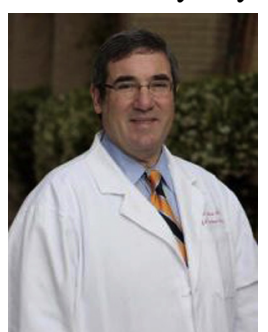

Dr R. Shemin (Los Angeles, Calif). I want to focus on 2 questions. One is you talk about the increased case load per surgeon. My thesis is that most cardiac surgeons and maybe thoracic surgeons in the United States are not performing the number of cases that our international colleagues are doing. I'd be interested if you have any specific numbers. I suspect that US surgeons perform 150 to 175 cases per year. It would not be unreasonable for most surgeons to be able to double that volume and still be satisfied with their careers.

The second thing is the pipeline. It takes many years to produce a thoracic surgeon. I don't think our society will ever stand in line waiting for cases to be done. There has to be enough demand, a long wait, and a need for international surgeons to join our work force and be able to provide services to patients. This is necessary to fill in the gap. So what are your thoughts on the case volume per surgeon? What are your feelings of the ABTS extending certification to the international thoracic surgeons?
Dr Moffatt-Bruce. We, as CT surgeons, are fairly resilient, and I think that inherently we probably do have the capacity to do more. However, I think the tension will be realized when we consider our inherent mandate is not only as clinicians but also as educators, administrators, and researchers. There will be a tension between those forces as we define ourselves as surgeons in whatever type of realm we're in, academic or community practice. We have to be careful and ultimately cognizant of these inherent tensions.

Introducing an international component to our American workforce is absolutely important. I think it depends on how you define international relative to North America compared with Europe and other great countries because there are different education and training paradigms. Ultimately, if there is a gap and there is untapped supply, then we need to look at lowering the barriers for our international colleagues to train and work in America. This will take some careful consideration, but it is a type of innovative thinking that we will need to meet the need.

Dr Moon. Let's finish up with 20 seconds, John, although I told you 30.

Dr Ikonomidis. Sure. We are in an interesting time in our specialty. The population is increasing, patients are aging, and at the same time CT surgery has been identified by surveys as the specialty occupied by the oldest surgeons. In 2009, an American College of Surgeons survey showed that more than $50 \%$ of practicing CT surgeons were aged more than 55 years and $12 \%$ were aged more than 70 years. It's only a matter of time before these individuals begin to retire, and in fact this has begun.

I think many of you, as I have, have received numerous emails about numerous job opportunities. Clearly the job market is expanding and I think is certainly indicative of this potential crisis situation. We need to continue to talk about this. I think we need to continue to look at this and respond with potential solutions as appropriate.

Dr Moon. Susan.

Dr Moffatt-Bruce. Considering the signs of trouble ahead, we have to go back to understanding the pipeline of CT surgeons. Looking at every opportunity to have trainees and the medical students enthusiastically embrace our discipline is going to be absolutely key and will ultimately serve to be our success going forward. 